\section{Modos de habitar periurbano en Santiago de Chile: megaproyectos residenciales cerrados y transformaciones en la vida cotidiana}

\author{
Víctor Suazo Pereda \\ ORCID: https://orcid.org/0000-0002-9319-0709 \\ Universidad de Chile \\ Correo electrónico: victor.suazo@ug.uchile.cl
}

\begin{abstract}
Resumen
Santiago de Chile ha experimentado procesos de expansión urbana caracterizados por la proliferación de espacios residenciales cerrados en su periferia metropolitana. Estos megaproyectos inmobiliarios abarcan grandes superficies de terreno y equipamientos de escala urbana, una nueva tipología habitacional que aspira ser una ciudad en sí misma. Pese a la abundante literatura en Latinoamérica, en Chile son escasas las investigaciones que exploran - desde la voz de sus propios habitantes- la relación entre este producto residencial periurbano y los modos de habitar de sus residentes. Mediante un abordaje etnográfico basado en jornadas de observación participante y entrevistas semiestructuradas, se evidencian cuatro dimensiones en las que un grupo de residentes ha visto transformados sus modos de habitar tras la llegada a un espacio residencial cerrado en la periferia metropolitana de Santiago: 1) movilidad cotidiana; 2) sociabilidad; 3) actividades cotidianas y acceso a servicios; 4) convivencia vecinal y estructuración del habitar. Se tensionan las visiones clásicas del miedo al crimen y la distinción social como motores del cerramiento residencial y se concluye en torno al creciente peso que adquieren los holdings inmobiliarios en la configuración de las periferias y sus efectos modeladores sobre los modos de habitar las metrópolis contemporáneas.
\end{abstract}

\section{Palabras clave}

Área metropolitana, modos de habitar, periurbanización, Santiago de Chile, urbanizaciones cerradas

\section{Peri-urban ways of living in Santiago de Chile: closed residential megaprojects and transformations in daily life}

\author{
Andrea Cárdenas Piñero \\ ORCID: https://orcid.org/0000-0003-3619-1294 \\ Universidad de Chile
}

\begin{abstract}
Santiago de Chile has experienced processes of urban expansion characterized by the proliferation of closed residential spaces in its metropolitan periphery. These mega real estate projects encompass large areas of land and urban-scale facilities, a new housing typology that aspires to be a city in itself. Despite the abundant literature in Latin America, in Chile there is little research that explores - from the voice of its own inhabitantsthe relationship between this peri-urban residential product and the ways of living of its residents. Through an ethnographic approach based on participant observation sessions and semistructured interviews, four dimensions are evidenced in which a group of residents has seen their ways of living transformed after arriving in a closed residential space on the metropolitan periphery of Santiago: 1) daily mobility; 2) sociability; 3) daily activities and access to services; 4) neighborhood coexistence and structuring of living. The classic visions of fear of crime and social distinction as engines of residential enclosure are stressed and it is concluded around the growing weight that real estate holdings acquire in the configuration of the peripheries and their modeling effects on the ways of inhabiting contemporary metropolises.
\end{abstract}

\section{Keywords}

Gated communities, metropolitan area, periurbanization, Santiago de Chile, ways of living 


\section{Introducción}

Los procesos de cerramiento residencial han cobrado fuerza en Latinoamérica desde la década de 1980 (Janoschka, 2002; Roitman, 2004). Al igual que otras metrópolis del subcontinente, Santiago de Chile experimentó una rápida proliferación de espacios residenciales cerrados durante los noventa e inicios del siglo XXI (Hidalgo et al., 2007; Meyer y Bähr, 2004; Sabatini y Cáceres, 2004; Salcedo y Torres, 2004). Sin embargo, en las últimas décadas, la localización y escala de este tipo de proyectos se ha modificado. De ser, hasta finales de los ochenta, pequeños condominios que no superaban la treintena de viviendas ubicados en áreas consolidadas del espacio urbano, pasaron a ser grandes urbanizaciones cerradas que bordeaban las 100 unidades de vivienda a mediados de los noventa y verdaderas "ciudades valladas" desde la primera década del 2000, es decir, megaproyectos residenciales cerrados que superan las 500 unidades de vivienda, abarcan mayores superficies de terreno y poseen equipamientos urbanos en las periferias metropolitanas (Hidalgo, 2004; Hidalgo et al., 2007; Vidal-Koppmann, 2008, 2012).

La sofisticación del mercado inmobiliario ha configurado una particular tipología habitacional que se ofrece como una ciudad en sí misma. Esta tipología rompe con los patrones clásicos del cerramiento residencial de finales del siglo XX y de suburbanización de las élites (Hidalgo, 2004; Vidal-Koppmann, 2008), dirigiéndose en el último tiempo hacia grupos pertenecientes a diversos sectores de clase media (Cáceres Seguel, 2015). En Chile estos megaproyectos periurbanos han sido desarrollados por holdings inmobiliarios que no solo diseñan y construyen, sino que también administran grandes porciones de territorio (Cáceres Seguel, 2016). Al alero de políticas neoliberales de desarrollo urbano condicionado, la producción de estos espacios residenciales cerrados ha contribuido a desencadenar procesos de expansión urbana y reproducción de grandes capitales económicofinancieros en la periferia metropolitana de Santiago (Lukas et al., 2020).

Desde comienzos del siglo XXI, la periferia metropolitana norte de Santiago ha experimentado un acelerado, pero selectivo proceso de desarrollo inmobiliario. Amparado en la figura legal de las Zonas de Desarrollo Urbano Condicionado (ZODUC), este desarrollo inmobiliario se ha materializado en formato de megaproyectos residenciales cerrados de baja densidad, orientados a grupos de sectores medios y altos, cuya escala de proyecto no tiene precedentes en Santiago (Hidalgo et al., 2007). La ZODUC es una figura de planificación territorial por condiciones que surge a partir de la modificación al Plan Regulador Metropolitano de Santiago de 1997, que incorpora la provincia de Chacabuco (Colina, Lampa y Til-til). Discursivamente, las ZODUC se plantearon como ciudades satélites diversas funcionalmente y heterogéneas socialmente. Sin embargo, la realidad actual difiere bastante de lo planificado.

En la práctica, las ZODUC consisten en vastas zonas de suelo anteriormente rural declarado como territorio urbanizable. En este sentido, se desencadenan movimientos especulativos de suelo con terrenos en los que no estaba permitido el desarrollo de actividad inmobiliaria dado su uso productivo, pero que presentan nuevas condiciones de uso sujetas a explotación de renta urbana. Colina se ha posicionado como la comuna con la mayor concentración de inversiones inmobiliarias asociadas a desarrollo urbano condicionado de las que hay previstas en todo el país. Para el quinquenio 20172021 se identificaron nueve iniciativas por USD $\$ 1.591$ millones, entre las cuales destacan los proyectos Piedra Roja (USD\$ 614 millones a ejecutar en el quinquenio), La Reserva (USD \$ 128 millones) y Santa Elena (USD \$ 425 millones) (Colina junto con otras dos comunas concentran un tercio de la inversión inmobiliaria de Chile a 2021, 2017). Esta última constituye el caso de estudio de la presente investigación.

Los megaproyectos residenciales cerrados han proliferado transformando los paisajes de las periferias metropolitanas y los modos de habitar de sus residentes en dimensiones que en Chile aún se les ha prestado escasa atención. En Latinoamérica existen algunas notables investigaciones que han abordado experiencias de habitar espacios residenciales cerrados en las periferias urbanas (Arizaga, 2005; Roitman, 2011; Svampa, 2001). En Chile, sin embargo, 
son menores las investigaciones que han buscado restituir la experiencia de vida en estos espacios desde la voz de sus propios habitantes. Al respecto, se destaca el trabajo de Cáceres Seguel (2015), quien -desde un enfoque cualitativo basado en la experiencia del periurbanita de clase media - tensiona las nociones de calidad de vida y satisfacción residencial, poniendo en entredicho la concepción de los espacios residenciales de la periferia metropolitana de Santiago como oasis de calidad de vida. En una línea similar, se plantea la siguiente pregunta de investigación: ¿cómo inciden los nuevos espacios residenciales cerrados periurbanos sobre los modos de habitar de sus residentes?

Frente a la escasa evidencia empírica para el caso nacional y el creciente volumen de producción que ha adquirido esta forma de urbanizar la periferia metropolitana de Santiago en las últimas décadas, el presente artículo tiene por objetivo general explorar la relación entre los nuevos espacios residenciales cerrados periurbanos y los modos de habitar de sus residentes. En definitiva, se plantea un doble propósito. Primero, enfocarse en los nuevos megaproyectos periurbanos, que han recibido menor atención que otras tipologías de espacios residenciales cerrados. Y, en segundo lugar, abordarlos "desde su interior", a diferencia de gran parte de las investigaciones precedentes en Chile. Para tal efecto, se trabaja con un caso de estudio ubicado en la comuna de Colina, en la periferia metropolitana norte de Santiago, uno de los territorios emblemáticos en la producción de espacios residenciales cerrados periurbanos (Lukas et al., 2020).

En las siguientes secciones se discuten los conceptos de cerramiento residencial, periurbanización y modos de habitar. Posteriormente, se presenta el marco metodológico, donde se expone el enfoque, técnicas, estrategias de acceso al campo y tipo de análisis de la investigación, además de antecedentes acerca del caso de estudio seleccionado. Luego, se evidencian los resultados de la investigación, donde se exponen, principalmente, las dimensiones en las que han sido transformados los modos de habitar de un conjunto de residentes tras su llegada a un espacio residencial periurbano en la comuna de Colina. Finalmente, se presenta una discusión de resultados y conclusiones.

\section{Cerramiento residencial, periurbanización metropolitana y modos de habitar}

Los procesos de cerramiento residencial se han vuelto un fenómeno planetario (Roitman, 2016). En Chile y Latinoamérica existe una vasta literatura que se ha masificado desde finales de los noventa e inicios de los 2000 (Cabrales, 2005; Roitman, 2004; Rojo, 2015). Buena parte de la literatura latinoamericana que trata el fenómeno del cerramiento residencial ha estado vinculada con procesos de fragmentación territorial (Borsdorf, 2003; Contreras et al., 2018; Janoschka, 2002), segregación residencial y distinción social (Arizaga, 2000, 2005; Roitman, 2003; Rosenmann, 2017; Ruiz-Tagle, 2016a; Sabatini y Cáceres, 2004, 2011; Svampa, 2001), privatización del espacio urbano (Caldeira, 2007; Pfannenstein et al., 2019); configuración de las periferias metropolitanas (Aguilar, 2002; Hidalgo et al., 2007; Vidal-Koppmann, 2008, 2012); modelos de gobernanza neoliberal (Cáceres Seguel, 2016), entre otros.

En Latinoamérica es posible identificar diversas perspectivas que han buscado explicar la proliferación de espacios residenciales cerrados. En primer lugar, la perspectiva del miedo al crimen es un abordaje ampliamente difundido por autores provenientes o influenciados por la escuela de Los Ángeles (Caldeira, 2007; Davis, 2003). Desde esta, el aumento de la criminalidad, la violencia urbana y la delincuencia serían los principales factores explicativos del cerramiento residencial por parte de las élites y grupos acomodados. Tales condiciones darían surgimiento a la "estética de la seguridad" (Caldeira, 2007) y la "militarización del espacio urbano" (Davis, 2003), donde dispositivos de control y vigilancia permean hacia diversos espacios del habitar. Lo anterior es cuestionado por autores que señalan una proliferación de espacios residenciales cerrados en ciudades con tasas de criminalidad muy disímiles (Chevalier y Carballo, 2005; Teixeira de Andrade, 2001). Junto con ello, plantean que asistimos a un incremento de la percepción subjetiva de inseguridad social que no siempre coincide con el 
aumento objetivo de la criminalidad (Borja, 2008; Carrión y Núñez, 2006).

Autores como Svampa (2001), Chevalier y Carballo (2005) y Roitman (2011) plantean que el fenómeno no solo se puede basar en el discurso de la seguridad, pues subsisten en el desarrollo de espacios residenciales cerrados estrategias de distinción y búsqueda de estatus social. Mientras Svampa hace alusión al vivir entre iguales, mediante el "entre nos", Chevalier y Carballo lo hacen a partir del "entre sí". De acuerdo con esta perspectiva de la distinción social, la búsqueda de exclusividad y diferenciación social entre grupos sería uno de los motores explicativos de la proliferación de espacios residenciales cerrados. En la misma línea, el surgimiento de un sentimiento antiurbano entre grupos acomodados de población contribuiría a explicar su "huída de la ciudad" (Arizaga, 2005).

Por su parte, Teixeira de Andrade (2001) señala que uno de los motores de la proliferación de espacios residenciales cerrados corresponde a la imposición de un estilo de vida, asociable al estatus social que significa la vida en un espacio residencial cerrado. En este sentido, Fernández et al. (2004) hacen referencia a la influencia que poseen las estrategias de marketing en la publicidad inmobiliaria para imponer en el mercado un producto residencial altamente exitoso para sus desarrolladores, en el que la fabricación mercantil de imaginarios y estilos de vida particulares ha tenido muy buena recepción por parte de las clases medias y superiores de la sociedad. De acuerdo con ello, habría un aprendizaje inmobiliario para instalar ciertos valores habitacionales deseables, aun cuando la búsqueda de seguridad ciudadana o distinción social no sean las motivaciones principales para el cerramiento residencial. Más recientemente, Cáceres Seguel (2015) analiza el impacto que tienen los proyectos residenciales privados periurbanos en la calidad de vida de sus habitantes. Ha demostrado que las motivaciones para habitar la periferia metropolitana no estarían en sentimientos antiurbanos - como ha argumentado parte de la literatura antes referenciada- sino que más bien, en la búsqueda de valores residenciales como espacio, seguridad y áreas verdes, que no se encontrarían en la ciudad consolidada.
Actualmente, existen diversas tipologías de espacios residenciales cerrados que han proliferado y se han diversificado de manera acelerada (Hidalgo, 2004), por lo que los factores explicativos del fenómeno no son atribuibles a causas únicas. Las características y motivaciones del cerramiento residencial no son generalizables en el tiempo, ni en los diversos territorios en los que este dinámico fenómeno ha tenido lugar, siendo un fenómeno complejo en el que dinámicas micro, meso y macrosociales, políticas y económicas se encuentran imbricadas.

En las últimas décadas, la escala del cerramiento residencial se ha hecho cada vez mayor, lo que ha derivado en una tipología habitacional que ha recibido denominaciones tales como megaproyectos (Meyer y Bahr, 2004; Stockins, 2004), pueblo privado (Vidal-Koppman, 2008) o ciudad vallada (Hidalgo, 2004), siendo una de las más recientes y de mayor escala. Constituyen grandes proyectos que aspiran a "ser ciudad" ubicados en territorios periurbanos, compuestos por un conjunto de condominios residenciales e incorporando elementos urbanos e infraestructuras de abastecimiento propio, buscando así, la autonomía del conjunto respecto de los territorios en los que se insertan (Hidalgo, 2004; Meyer y Bahr, 2004; Stockins, 2004; Vidal-Koppman, 2012). Su localización en las periferias metropolitanas asoma como cualidad distintiva, contribuyendo al desarrollo de intensos y dinámicos procesos de periurbanización caracterizados por la pérdida de suelos agrícolas, deterioro de paisajes naturales y ecosistemas, urbanizaciones privatizadas de baja densidad, infraestructuras de movilidad tipo autopistas, lo que configura territorios en disputa entre lo urbano y lo rural (Lukas et al., 2020).

En Chile los procesos de expansión metropolitana se han dado al alero de políticas neoliberales y tras fuertes presiones ejercidas por grandes grupos económicofinancieros nacionales y transnacionales que han pujado desde la dictadura hasta la actualidad por la expansión de límites urbanos y condiciones favorables para el desarrollo inmobiliario (Lukas et al., 2020). Con la implementación del neoliberalismo en Chile durante la dictadura cívicomilitar liderada por Augusto Pinochet (1973-1990) y su 
profundización durante los 30 años venideros, se produjo un proceso de transformación político-económico basado en el desmantelamiento del Estado como ente proveedor de servicios básicos a la ciudadanía. Privatización de servicios y empresas públicas, liberalización económica, desregularización, apertura económica internacional, reducción de impuestos corporativos, subsidiariedad del Estado, entre otros, son algunos de los principios que se han materializado también en el ámbito territorial: liberalización de límites urbanos, desregularización de mercados de suelo, flexibilización normativa de instrumentos de planificación territorial, entre otros.

Una de las expresiones más elocuentes la constituye la Política Nacional de Desarrollo Urbano (PNDU) de 1979, cuyos principios básicos postulaban que: 1) el suelo urbano no es un recurso escaso; 2) los mercados son los mejores asignadores de tierra entre los distintos usos; y 3) el uso del suelo debe regirse por disposiciones flexibles, definidas por los requerimientos del mercado (Sabatini, 2000). A partir de las reformas neoliberales iniciadas en la década de los setenta, se comienza a consolidar un influyente sector inmobiliario en Santiago - conformado por holdings empresariales- que ya no solo limita sus funciones a construir, sino que también a la gestión de grandes superficies de suelo, la promoción de compra y venta del producto y la proyección de sus inversiones en aquellos sectores de la ciudad que impliquen mayor rentabilidad (Hidalgo et al., 2007). Gracias a ello se produce una importante metamorfosis urbana que surge de la estrecha relación entre el Estado y el mercado y que se sintetiza en la noción de holdingbanism (Cáceres Seguel, 2016).

Con la modificación del Plan Regulador Metropolitano de Santiago de 1997, que incorpora la provincia de Chacabuco (Colina, Lampa y Til-til), se implementaron las ZODUC $^{1}$ y AUDP ${ }^{2}$, dos nuevas figuras de la planificación territorial chilena que darían paso a los megaproyectos residenciales cerrados (Stockins, 2004) y que, en definitiva, habilitaron la urbanización del territorio como forma de movilización y reproducción de grandes capitales en las periferias metropolitanas (Lukas et al., 2020). El mismo año se promulgó también la Ley $\mathrm{N}^{\circ} 19.537$ de Copropiedad Inmobiliaria, la cual establece que cada conjunto debe elaborar su propio reglamento, una evidencia más del traspaso de responsabilidad regulatoria estatal al ámbito privado.

En definitiva, las lógicas neoliberales han incitado y materializado un modelo de metropolización ampliada caracterizado por la periurbanizacón, una ciudad de cobertura regional con configuración policéntrica, tipo archipiélago, con límites imprecisos entre lo urbano y lo rural, distinto a la ciudad del período desarrollista fordista, cuando el fenómeno de centros y periferias resultaba más nítido (Riffo, 2004). Estos procesos de expansión metropolitana se relacionan con lo que Jirón y Mansilla (2014) denominan urbanismo fragmentador, proceso en el cual la transformación del espacio urbano tendría consecuencias directas sobre la vida cotidiana de sus habitantes.

En estudios urbanos, las investigaciones que centran su atención en los modos de habitar integran en el análisis al sujeto y su experiencia diaria o se indaga en cómo se configura la espacialidad de la vida cotidiana (Jirón y Mansilla, 2014). En este sentido, habitar supone no solo el uso de las estructuras físicas ya establecidas, sino que involucra la forma en que los habitantes producen y despliegan sus propias vidas (Segura y Chaves, 2019). Desde la economía política urbana, la dialéctica socioespacial implica que estructuras espaciales y sociales se determinan mutuamente, siendo el espacio socialmente construido, a su vez, un factor influyente en las relaciones sociales (Lefebvre, 1991). En esta línea, procesos de producción del espacio permean, influyen o moldean las prácticas, percepciones y vida cotidiana de los sujetos (Ruiz-Tagle, 2016b), esfera de producción de relaciones sociales que autores como Lefebvre (2003) reconocen como principal campo de disputa y transformación radical de la realidad.

1 Zonas de Desarrollo Urbano Condicionado.

2 Áreas Urbanizables de Desarrollo Prioritario. 
Figura 1

Localización de la ZODUC Santa Elena en el Área Metropolitana de Santiago

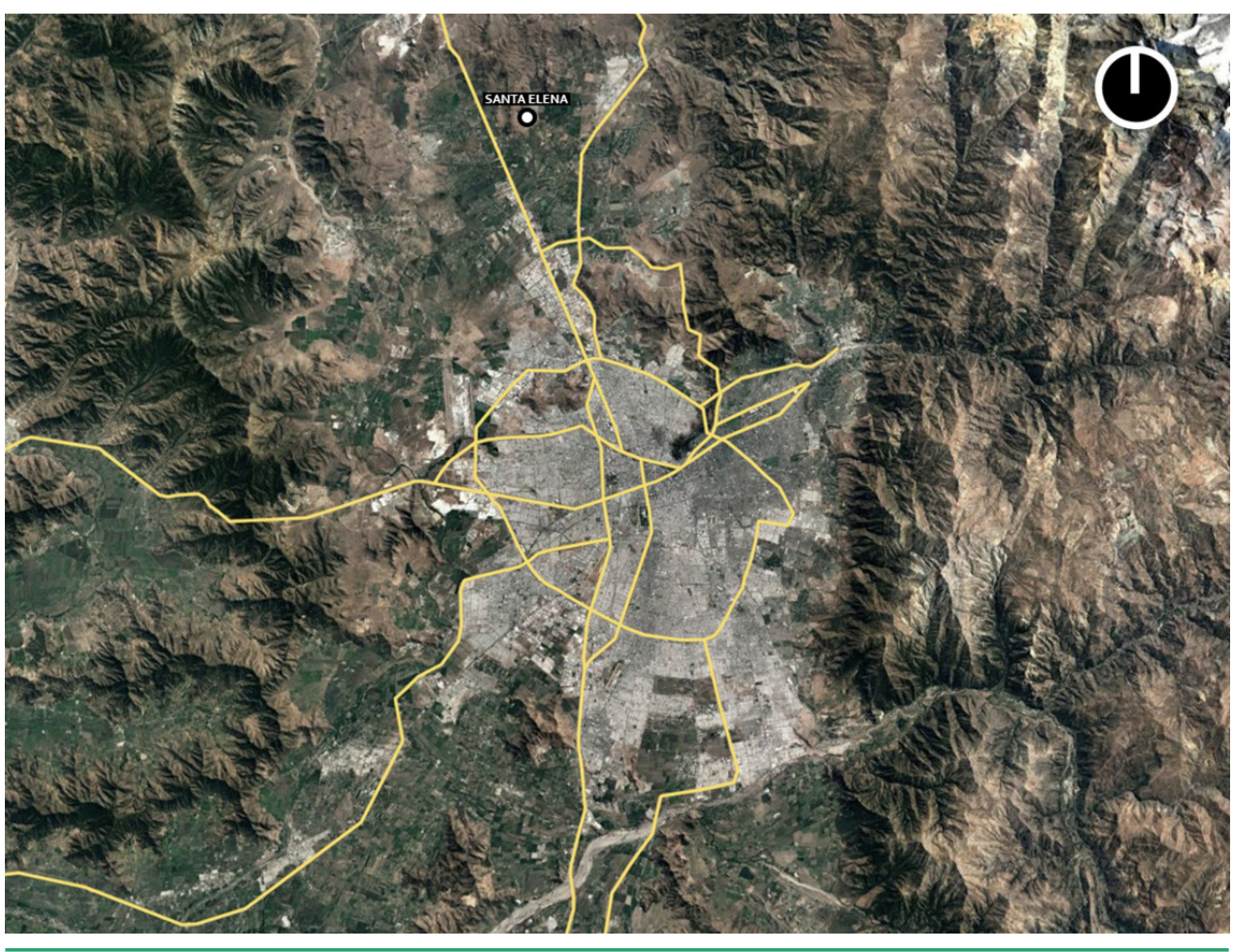

Existe una literatura reciente en torno a la experiencia de habitar las periferias urbanas de grandes y medianas ciudades latinoamericanas, en las cuales se ponen en juego factores como las prácticas y experiencias, significados y representaciones que asignan los habitantes (Espinosa, 2019; Espinosa et al., 2015). En Chile, sin embargo, siguen siendo muy menores las investigaciones que han buscado restituir la experiencia de vida en los espacios residenciales periurbanos desde la voz de sus propios habitantes. Al respecto, se destaca la investigación de Cáceres Seguel (2015), quien -desde un enfoque cualitativo - tensiona las nociones de calidad de vida y satisfacción residencial en estos espacios de la periferia metropolitana de Santiago, desde la experiencia del periurbanita de clase media.

\section{Santa Elena Ecoube: caso y enfoque metodológico}

El presente artículo se sustenta en un estudio de caso realizado sobre "Santa Elena, Ecourbe", una Zona de Desarrollo Urbano Condicionado (ZODUC) emplazada en la comuna de Colina, provincia de Chacabuco, periferia metropolitana norte de Santiago (Figuras 1, 2, 3). Consiste en un megaproyecto inmobiliario que se ha configurado desde el año 2006 sobre la base de un conjunto de condominios cerrados desarrollados por el consorcio de las inmobiliarias Agsa, Grupo Avellaneda, Imsa Adportas, Fernández Wood S.A. y Siena. Al año 2019 se habían construido cerca de 1.100 viviendas en 100 hectáreas con precios iniciales de venta cercanos a las $5.900 \mathrm{UF}^{3}$, hasta valores que fluctúan entre las $7.000 \mathrm{y}$ 9.000 UF en la actualidad. Su capacidad total proyectada es para 10.700 unidades en 1.950 hectáreas de terreno a 40 años plazo, lo que lo sitúa como el segundo mayor proyecto inmobiliario en la comuna tras Piedra Roja (Gutiérrez, 2019).

Se ubica entre las autopistas Los Libertadores y la Ruta 5 Norte, lo que permite tiempos de viaje de 25 minutos aproximados hasta el centro de Santiago. El proyecto aspira a ser una nueva ciudad satélite integral. Actualmente, cuenta con equipamientos tales como colegio privado, jardín infantil y sala cuna, stripcenter, centro deportivo, equipamiento recreativo y laguna artificial (Figuras 4, 5,

3 Unidad de Fomento (UF) es una unidad de cuenta utilizada en Chile, reajustable según inflación. A febrero de 2021, 1 UF era equivalente a CLP\$29.120 (USD\$39,63). 
Figura 2

Entorno inmediato

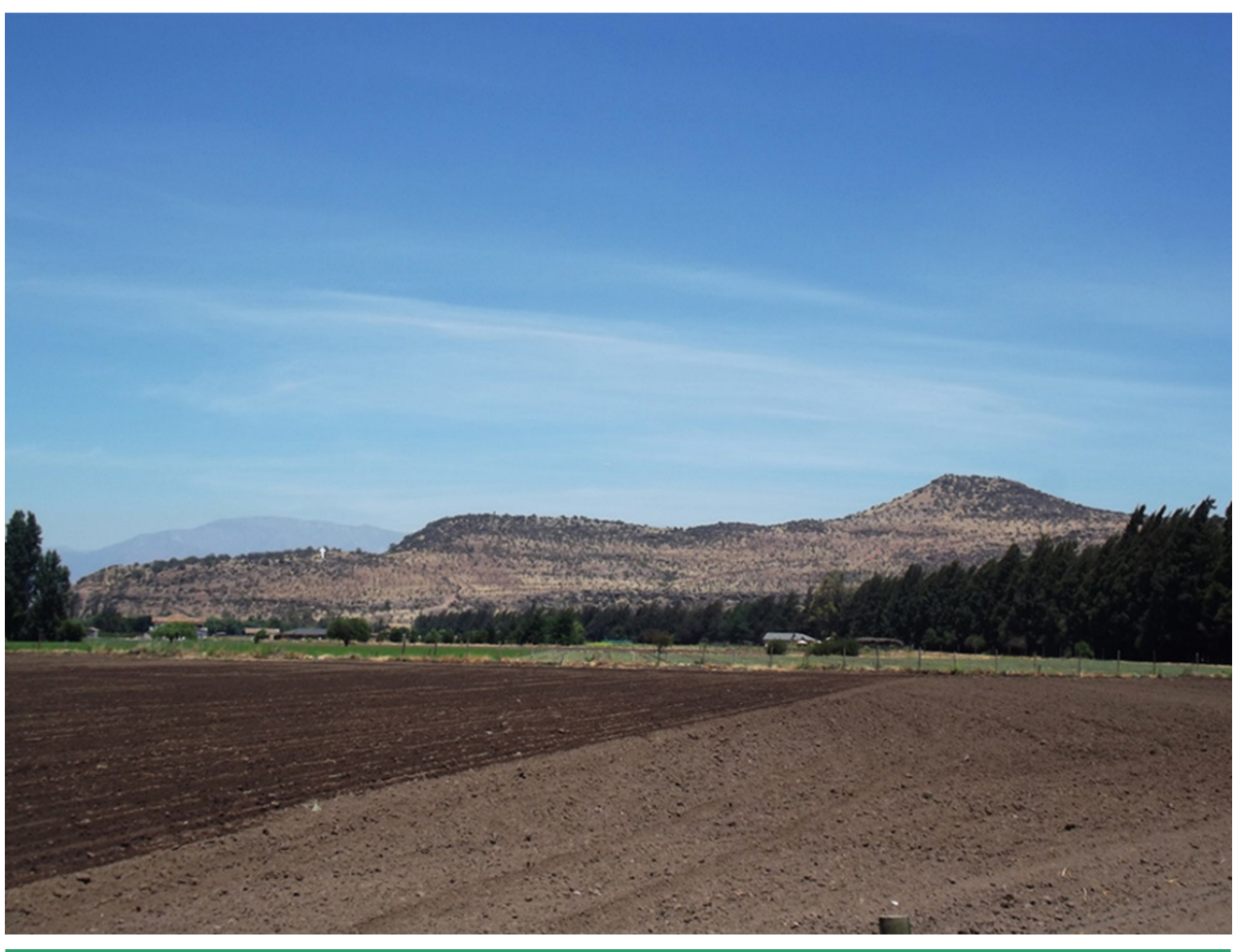

Figura 3

Control de acceso a Santa Elena

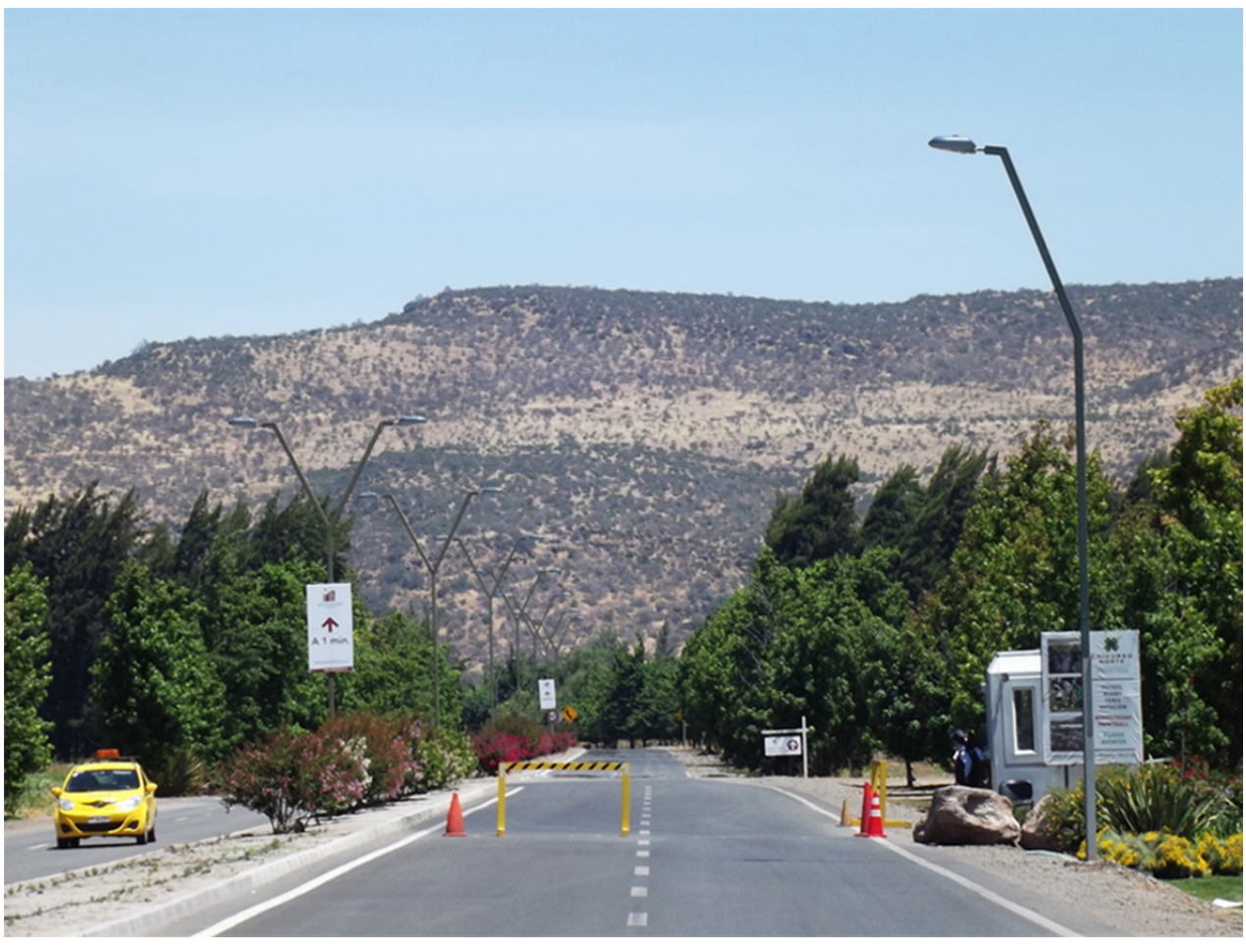




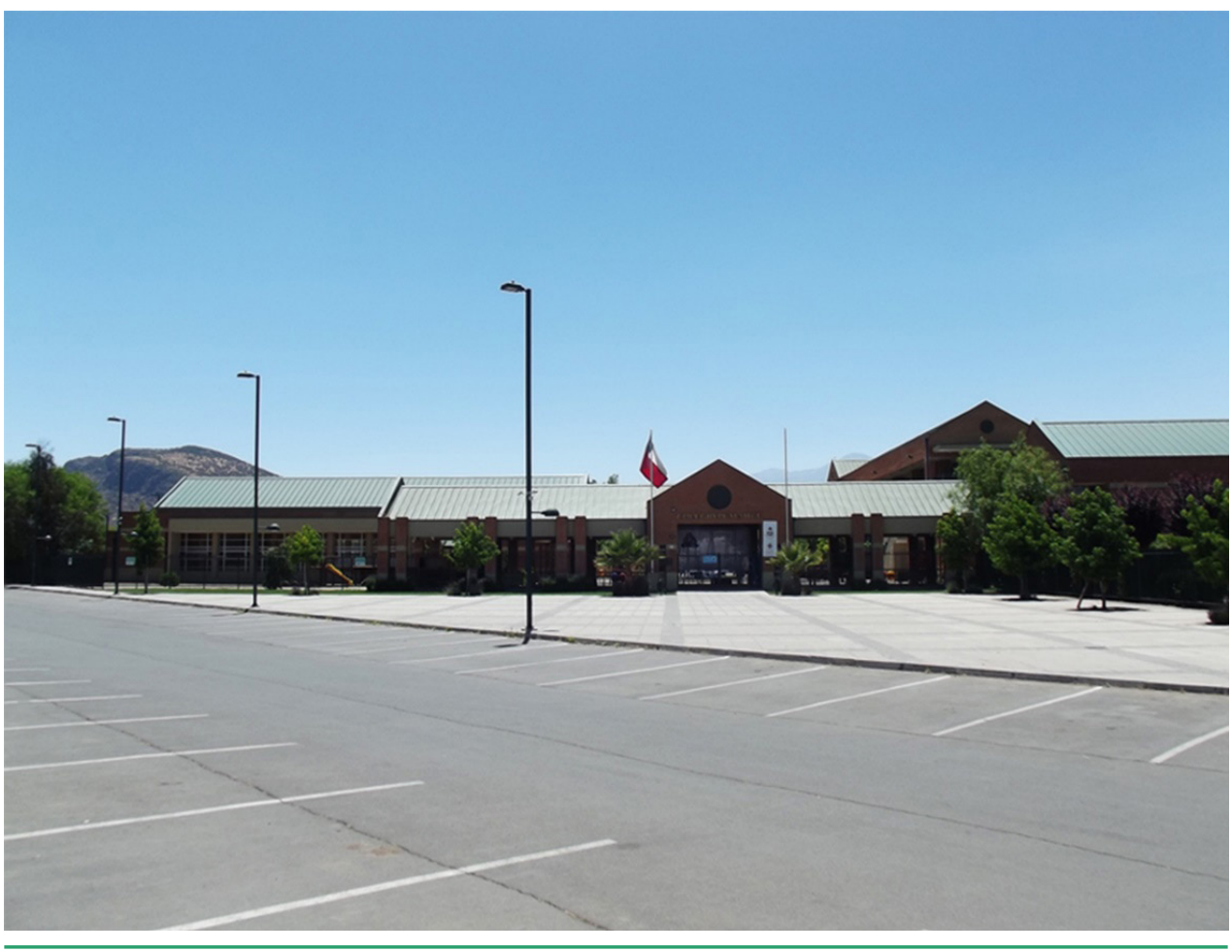

Figura 5

Jardín infantil

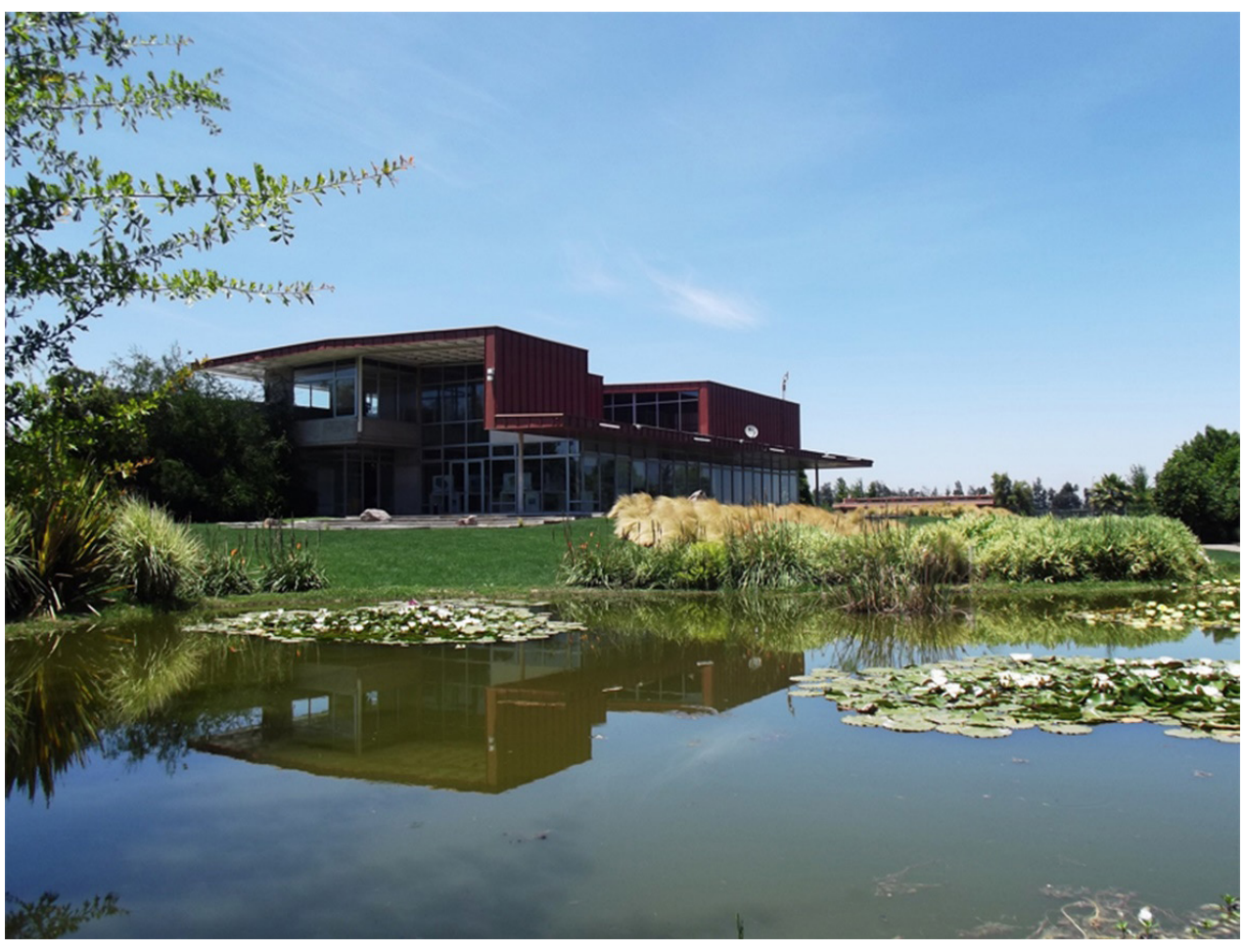




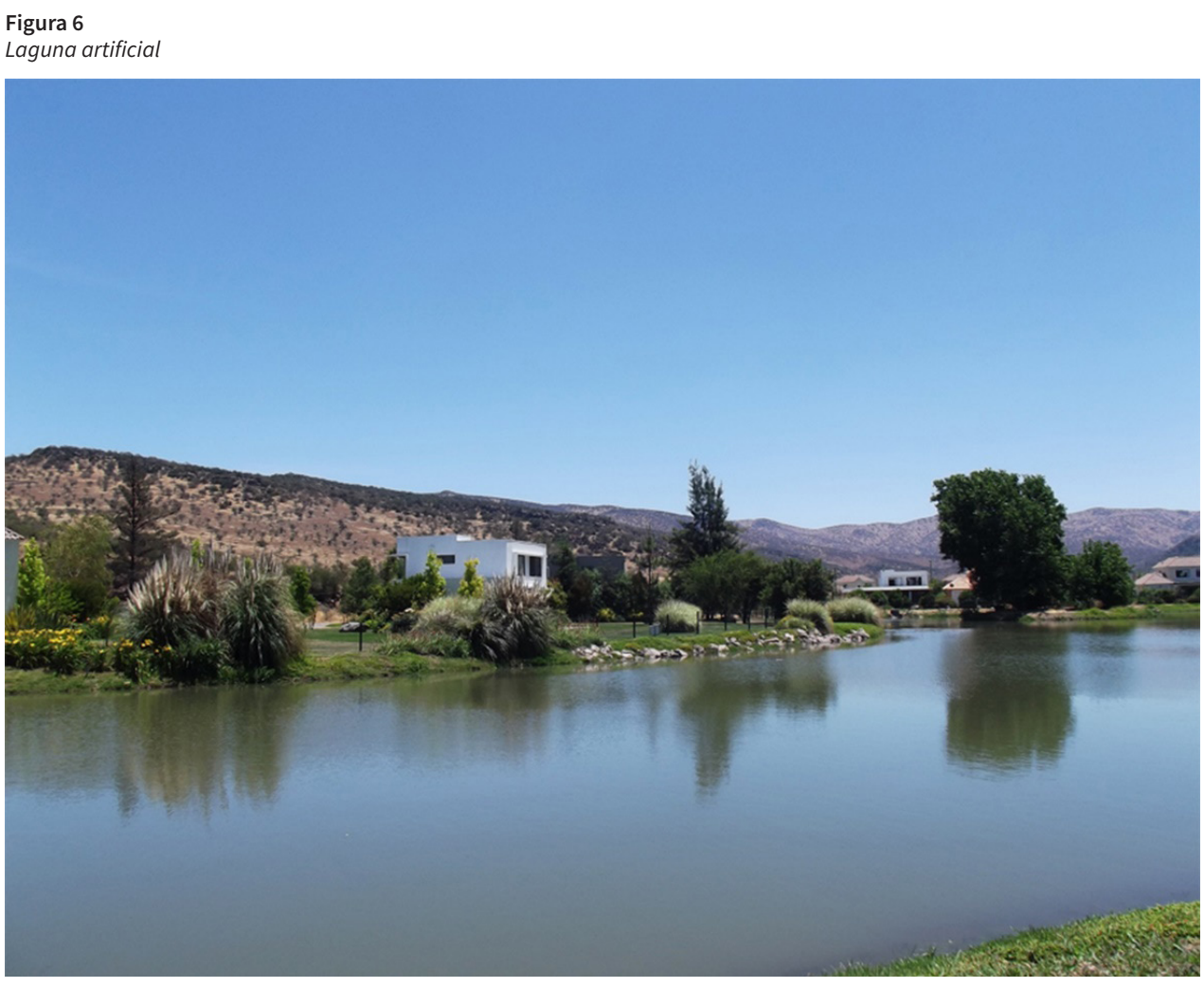

6), esta última pese a los conocidos problemas de escasez hídrica en la provincia (Lukas et al., 2020)

El estudio presenta un sustento metodológico de tipo cualitativo con un carácter exploratorio-descriptivo. El abordaje etnográfico resulta fundamental para comprender cómo viven los habitantes de un espacio residencial cerrado periurbano con un enfoque "desde el interior", a diferencia de gran parte de las investigaciones precedentes a nivel nacional. La etnografía constituye una práctica y concepción de conocimiento que busca comprender los fenómenos sociales desde la perspectiva de sus miembros (Auyero y Swistun, 2007; Guber, 2011). Dadas las estrictas medidas de seguridad y control de acceso a estos espacios residenciales cerrados, se contactó previamente a un residente del condominio como informante clave, quien actuó como primer vínculo para acceder al campo y al resto de los habitantes, tal como lo han realizado investigaciones precedentes en la materia (Svampa, 2001).

Las principales técnicas de producción de información fueron entrevistas semiestructuradas a residentes de la urbanización y a actores clave, además de jornadas de observación participante. En primer lugar, se aplicaron
18 entrevistas semiestructuradas con residentes de los condominios y extensas jornadas de observación participante durante el año 2014. Tras las primeras entrevistas, se prosiguió con la bola de nieve y la selección de participantes se definió por criterios de saturación de información, es decir, se realizaron entrevistas hasta que la última de ellas dejara de aportar nueva información a la investigación. Posteriormente, durante el primer semestre del año 2018, se aplicaron cinco entrevistas adicionales con nuevos participantes, a fin de actualizar y validar información.

En total se realizaron 23 entrevistas a residentes cuyo tiempo de residencia en Santa Elena no superaba los tres años. La pauta de entrevista se estructuró en torno a los siguientes temas: caracterización del habitante, composición del hogar y trayectoria residencial; motivaciones y preferencias residenciales para vivir en Santa Elena; movilidad y actividades cotidianas, formas de sociabilidad, relación con la ciudad consolidada, entre otras. La información de las entrevistas fue analizada mediante una codificación abierta, en primera instancia y, luego, una codificación axial, buscando puentes con elementos teóricos clave. 
Figura 7

Niños en espacio común

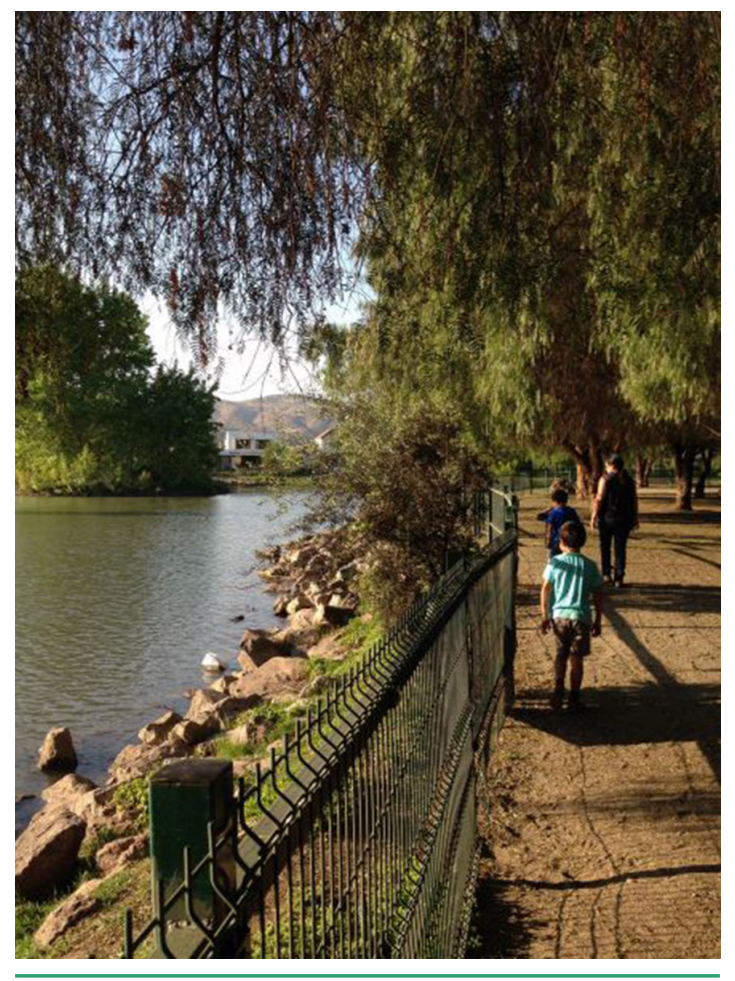

Asimismo, se desplegaron diversas jornadas de observación participante. Este proceso supone la presencia prolongada en el condominio y con sus residentes, en otras palabras, "estar allí" (Guber, 2011). Ello implica una fase conjunta de observación y participación, comprendiendo que "se participa para observar y que se observa para participar” (Guber, 2011, p. 57). En este sentido, se asistió periódicamente al conjunto en distintos horarios y días de la semana, se hizo uso de sus espacios comunes y servicios de transporte, se participó en diversas instancias realizadas en su interior, tales como actividades recreativas, deportivas y reuniones administrativas, tal como si se fuera un residente más. La información fue registrada a través de grabaciones de audio, notas de campo y fotografías.

La edad de los entrevistados fluctuó entre los 30 y 45 años. La composición familiar suele ir entre tres y cinco integrantes, en su mayoría, familias jóvenes con núcleos biparentales tradicionalmente constituidos con hijos pequeños que no superan la etapa de preadolescencia o hijos "en camino", grupo coloquialmente llamado babies on board (Svampa, 2001). Gran parte de las entrevistas fueron aplicadas con la presencia de ambos miembros de la pareja, reconociendo el perfil predominante de núcleos biparentales. No obstante, existen también hijos que rompen con esa mayoría, quienes están en etapa adolescente e incluso universitaria lo que, consecuentemente, implica que algunos de los integrantes de la familia lleven un modo de vida poco habitual con respecto al común de los residentes.

En su gran mayoría, el perfil de la población que reside en Santa Elena no forma parte de la élite histórica o tradicional chilena. Más bien conforma una clase media ascendente. En su mayoría, ambos integrantes de la pareja son profesionales y aportan con ingresos al hogar de forma conjunta. Algunos de ellos poseen también estudios de posgrado. Entre las profesiones de los entrevistados figuran abogados, contadores, bioquímicos, constructores, ingenieros con distintas especialidades (civil, electrónico, en computación, eléctrico, en alimentos, ambiental), entre otros. De acuerdo con su nivel de ingresos, todos los entrevistados se encuentran en el quinto quintil. Por otra parte, la trayectoria habitacional de los residentes permite intuir su posición de ascenso y ciclo familiar dentro de la estructura social metropolitana. Muchos de ellos crecieron en viviendas unifamiliares ubicadas en comunas como Macul, Cerro Navia, San Bernardo, Independencia, Conchalí, San Miguel, Maipú, entre otras 


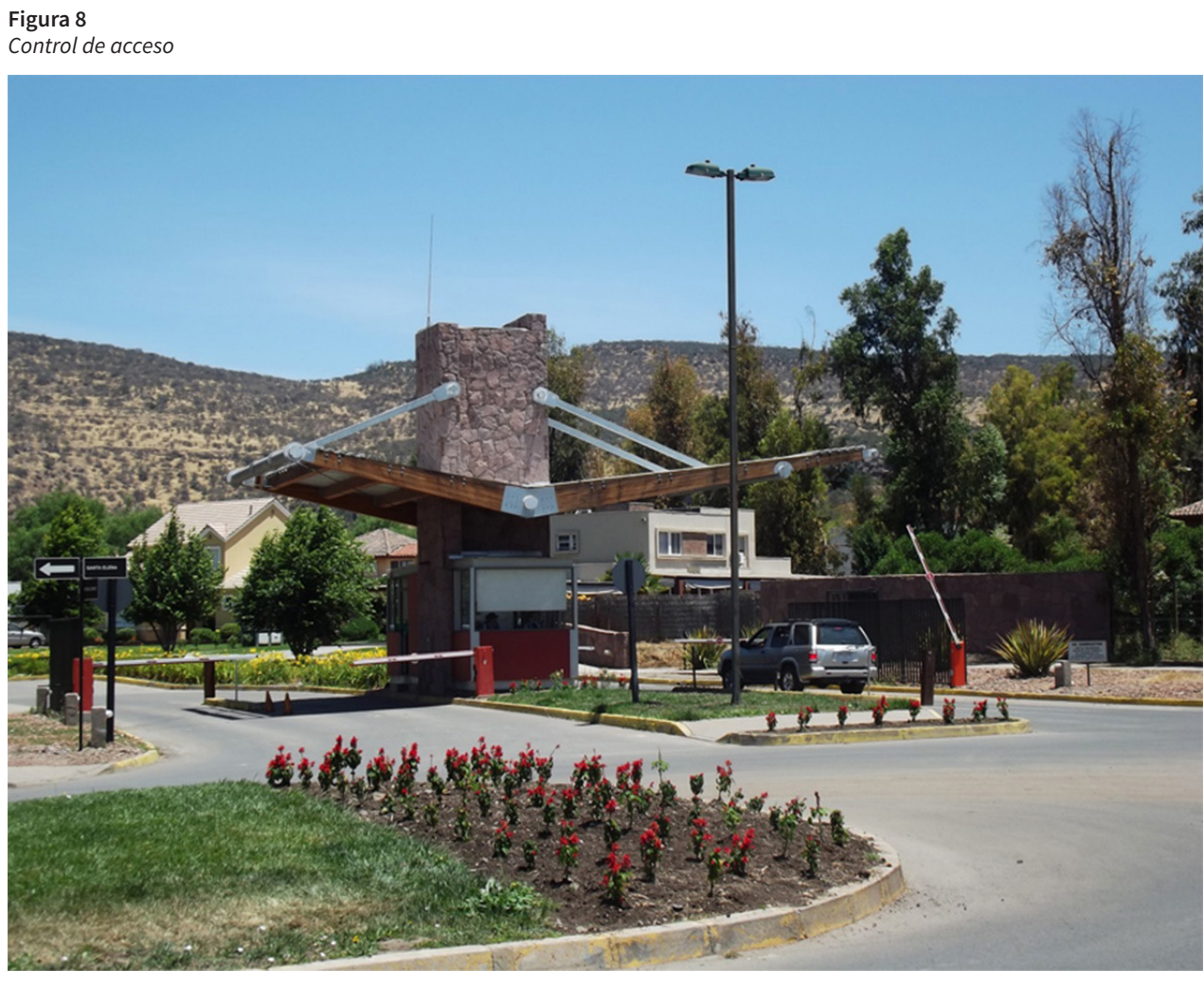

comunas que no forman parte del cono de alta renta de la ciudad y que suelen ser asociadas a estratos populares.

\section{Resultados}

\section{Motivaciones del cerramiento residencial periurbano}

Las motivaciones para vivir en un espacio residencial cerrado en la periferia metropolitana de Santiago son diversas. El principal motor del cambio residencial se sintetiza en la búsqueda de atributos habitacionales concebidos como adecuados para "hacer familia", tales como: ausencia de contaminación ambiental en comparación con la ciudad consolidada, mayores superficies de vivienda y de terrenos individuales en relación con otras comunas de Santiago y precio acorde a sus capacidades de endeudamiento, vivienda unifamiliar aislada y con patio como garante de tranquilidad y privacidad. En definitiva, la búsqueda de un entorno físico, social y ambiental que reúne una meticulosa selección de valores urbanos, de la cual se excluyen la experiencias indeseadas y espontáneas de la ciudad abierta.

Las personas que decidimos venirnos para acá o a lugares como este (...) es venir a formar familia.
Es el entorno ideal para formar familia con ciertos valores que uno quiere entregar. (Ingeniero, 40 años).

La alusión a la seguridad es una constante entre los entrevistados. Las medidas de control de acceso y seguridad, tales como rejas, cámaras de vigilancia y cercos eléctricos, son atributos ampliamente valorados, más aún, dada la dependencia laboral de los residentes con la ciudad consolidada que implica que pasen gran parte del día fuera del condominio (Figuras 8 y 9). Sin embargo, en ningún caso se declara la búsqueda de seguridad como detonante del cambio residencial hacia Santa Elena y, por ende, como motivo del cerramiento residencial. Incluso, el discurso en torno a la búsqueda de seguridad adquiere significados más amplios y complejos que el miedo al crimen, la delincuencia o la violencia urbana. Refiriéndose a la protección ante los robos y asaltos, Valentina comenta lo siguiente:

yo no lo veo tanto por eso. Yo lo veo porque, si mi hijo está jugando en la calle y viene un gallo a exceso de velocidad (...) el gallo no está pensando: "oye, aquí puede haber un barrio residencial, puede que haya niños jugando, voy a pasar más lento". El gallo pasa rápido igual... y el niño sale detrás de una pelota... 


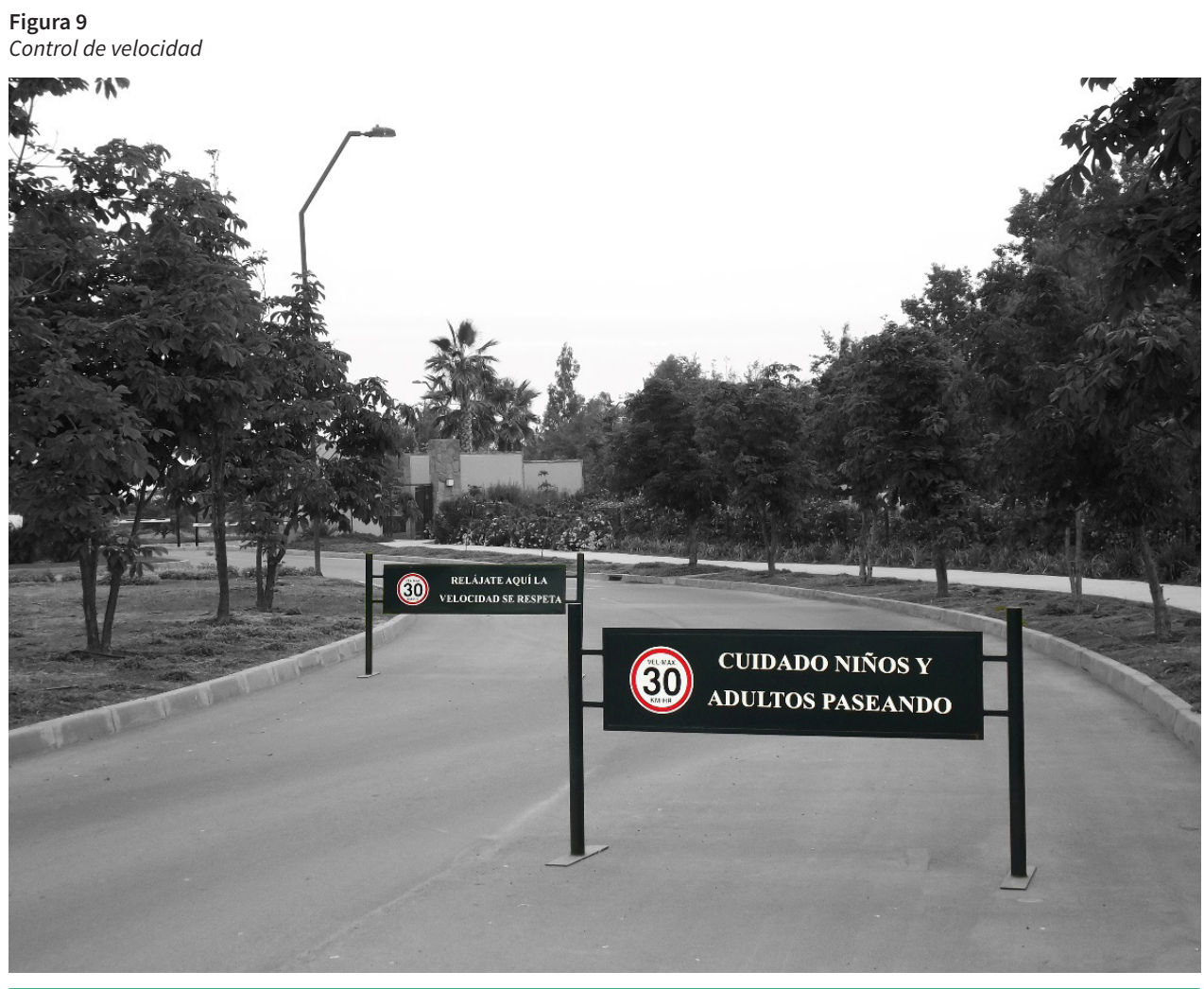

esas son las preocupaciones que como mamá uno tendría con un niño, más que la propia seguridad de la delincuencia... porque si tú tenís en tu casa alarma, tenís la reja, tenís todas esas cosas, ya es como menos probable que puedan entrar [a robar]. La percepción de inseguridad va más que nada por el peligro de la salud, más que porque te puedan robar algo. (Terapeuta ocupacional, 35 años).

La seguridad es un concepto complejo que no debe reducirse solo al miedo al crimen. Los testimonios de los residentes dan cuenta de que está asociada a mantener el control sobre las diversas áreas o dimensiones de la vida. La posibilidad de llevar una vida "segura", entendida como una vida exenta de conflictos e imprevisiones. Por consiguiente, la "tranquilidad" se puede interpretar como la capacidad que poseen los residentes (padres principalmente) para controlar su entorno inmediato. En palabras de una entrevistada, tener la certeza "que los niños estén tranquilos, estén en un ambiente seguro y en un buen ambiente". (Visitadora médico, 39 años).

Para gran parte de los entrevistados, vivir en condominio (Figura 10) y habitar la periferia metropolitana surge como consecuencia de la búsqueda de otros atributos habitacionales, la relación con su capacidad de endeudamiento y no necesariamente de la búsqueda declarada de distinción social o miedo al crimen al que suele asociarse el cerramiento residencial. Los entrevistados valoran atributos habitacionales como el patio, mayores superficies de terreno y vivienda y espacios para los hijos (Figura 7), evidenciando el peso del ciclo de vida familiar en la toma de decisiones residenciales. Frente a la pregunta por sus motivaciones para vivir en un espacio residencial cerrado, Jéssica comenta lo siguiente:

nos cambiamos porque tiene el colegio cerca, por los espacios que hay acá... y coincidió que es condominio, pero... una cosa al azar que era condominio... si lo que buscábamos era una casa con más patio. (Ingeniera en alimentos, 44 años).

En la misma línea, algunos entrevistados aluden a las dificultades para hallar viviendas con patio en otras modalidades residenciales ofrecidas en el mercado habitacional acorde a su capacidad de endeudamiento y expectativas, por lo que el cerramiento residencial periurbano surgiría como consecuencia de la oferta de viviendas en Santiago, tal como evidencia el siguiente relato. 
Figura 10

Interior condominios

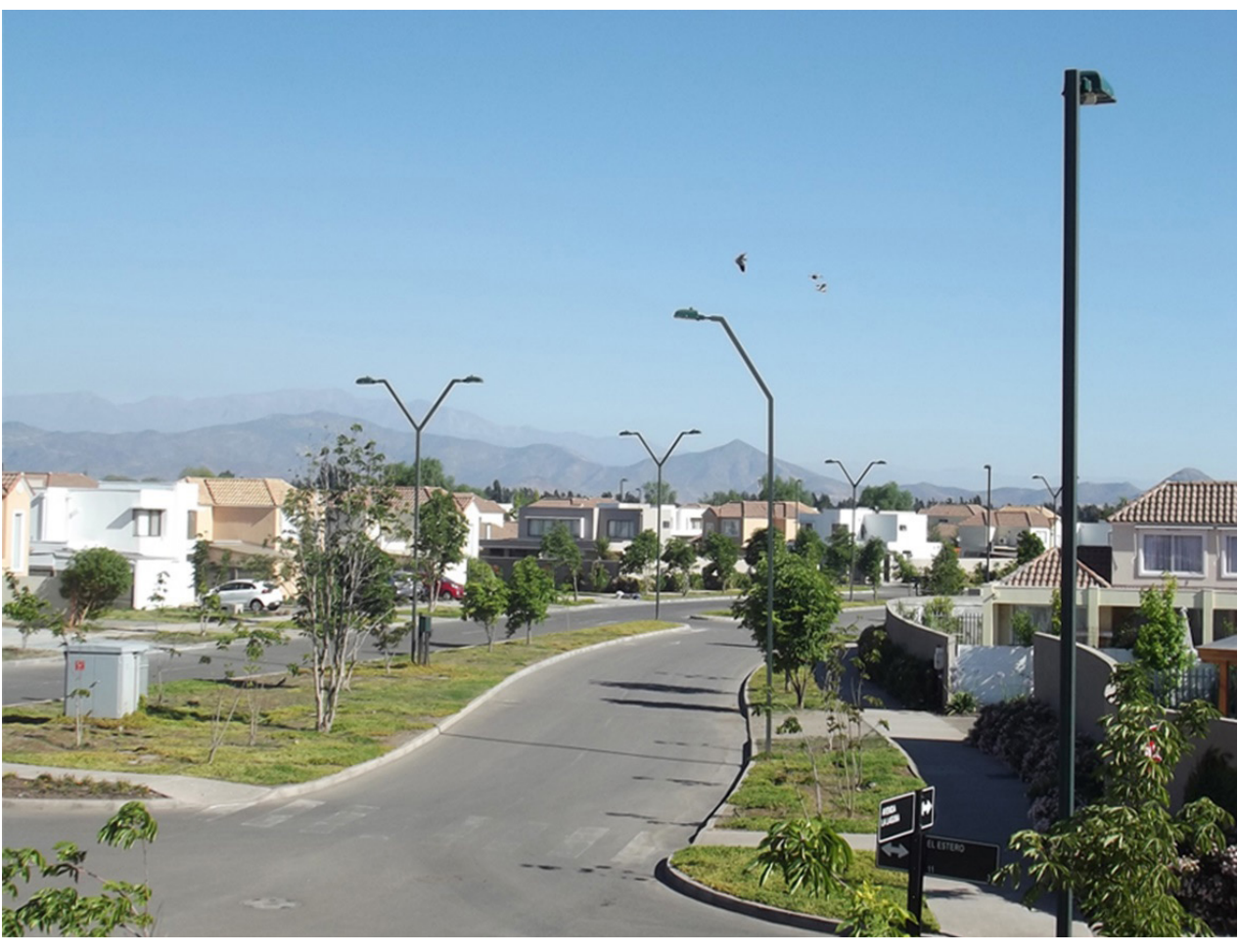

necesitábamos casa. Queríamos casa para darle patio, para tener más espacio de juego para los niños... y eso lo encontramos en un condominio. No era fácil encontrar casa con patio grande que no fuera en un condominio. (Ingeniero civil, 33 años).

Francisco describe la selección de Santa Elena en la "relación precio-terreno" acorde a sus capacidades de pago y endeudamiento, en comparación con otras comunas del área consolidada de Santiago con similares estándares residenciales. El arribo a un espacio residencial cerrado en la periferia metropolitana estaría vinculado con la búsqueda de acceso a tales atributos habitacionales como el patio, la casa y las mayores superficies de terreno y vivienda y no precisamente, por un sentimiento antiurbano, tal como evidencian los siguientes relatos.

Peñalolén. Huechuraba. Colina. Son las únicas opciones que tenís de casa acá en Santiago. Peñalolén tiene una conexión que es un desastre, ¿cachai? Las casas son, además, mucho más caras y... no sé po', en salir de Peñalolén te podís demorar 40 minutos, 45 minutos fácil. Así que: descartado. Huechuraba lo mismo. Pedro Fontova era un desastre, ahora lo están arreglando, pero era un desastre (...) y, además, tenía las casas demasiado juntas y los terrenos demasiado chicos (...). Había casas del mismo metraje de estas y a... 500 o 600 UF más, donde teníai al vecino justo al lado y un patio que era... hasta donde termina nuestra terraza y chao po', ¿cachai? (...) Entonces, al final fue relación precio y terreno. (Ingeniero civil, 31 años).

Buscamos casa en otros lugares, pero el costo era más caro, estaba más contaminado y los patios eran un cuarto del patio que ofrecían acá. Entonces, preferimos la distancia versus la cantidad de patio que teníamos. (Terapeuta ocupacional, 35 años).

El acceso a valores habitacionales como el patio, la casa aislada y las mayores superficies de vivienda y terreno son percibidos por los propios entrevistados como un incremento en su calidad de vida. No obstante, emergen una serie de transformaciones en la vida cotidiana de los residentes que, en algunos casos, implican altos costos económicos y sociales. Tales transformaciones son, en palabras de una entrevistada, "parte del precio extra" de acceder a los valores habitacionales como los ofrecidos en Santa Elena. A continuación, se exploran cuatro dimensiones en las que un grupo de habitantes ha visto transformados sus modos de habitar tras la llegada a un 
espacio residencial cerrado en la periferia metropolitana de Santiago, a saber: 1) movilidad cotidiana; 2) sociabilidad y redes; 3 ) actividades cotidianas y acceso a servicios; 4) convivencia vecinal y estructuración del habitar.

\section{Transformaciones en la movilidad cotidiana}

Gran parte de los entrevistados mantiene sus redes laborales en comunas de la ciudad consolidada. La búsqueda de mayores superficies de terreno implica una mayor distancia con respecto a redes laborales prestablecidas y, por ende, un mayor gasto económico en el traslado diario. El cambio de residencia a Santa Elena constituye un incremento de las distancias y en los costos económicos para la movilización. Frente a la inexistencia de redes de transporte público en el sector, se genera una dependencia del automóvil y, en consecuencia, un mayor desgaste de este último, además de la pérdida de alternativas de medios de transporte en relación con la ciudad consolidada. No obstante, es un "precio extra" que se asume y se compensa con el acceso a mayores superficies de terrenos y tranquilidad, entre otros atributos.

Si comprábamos un departamento o una casa en Ñuñoa, me tomaba 50 minutos en llegar a la pega. Ya sea si me voy en metro, si me voy en auto, en bicicleta o lo que sea... era alrededor de 40-50 minutos, que es lo mismo que me demoro hoy en día acá, ¿cachai? porque aquí es carretera directo ¿te fijai? Claro, hay costos más altos, digamos, porque, como la distancia es más grande, los autos se desgastan más, el costo de la bencina es mayor, pero todo eso se compensa con que aquí tú encontrai terrenos más grandes. Hay mayor tranquilidad. (Ingeniero civil electrónico, 34 años).

El incremento de las distancias y la pérdida de alternativas de transporte tiene repercusiones más agudas en la experiencia de movilidad de otros residentes, por ejemplo, los jóvenes con actividades educacionales fuera del condominio. Santa Elena cuenta con bus privado exclusivo que conecta este espacio residencial con la ciudad consolidada, el cual termina su recorrido en la estación intermodal Vespucio Norte, ubicada en el límite entre las comunas de Recoleta y Huechuraba. El bus cuenta con horarios predefinidos para realizar viajes entre el mismo punto de origen y destino. La restricción horaria con la que funciona este sistema de transporte y su limitada frecuencia diaria representa una dificultad en la vida cotidiana de los residentes que utilizan el servicio, pues sus actividades diarias comienzan a extenderse y planificarse en función de los horarios del bus.

Yo antes [cuando vivíamos en Huechuraba] salía de la U a las 13:30 y me iba directo a la casa... o si salía más temprano de la U, no sé a la... una, de ahí me podía ir directo a la casa. Pero ahora, si salgo a la una, igual solo puedo tomar el bus de las 15:45 y con esa hora de salida [del bus] estoy condicionada... me tengo que quedar en la U. Entonces, al final como que, a pesar de que el tiempo de viajar para acá es corto, es media hora [desde el metro Vespucio Norte] y quizás me demoro 15 minutos más de lo que me demoraba en llegar antes a la casa [en Huechuraba], yo creo que el tiempo de transporte para mí se alarga mucho más porque son muchas horas que tengo que estar sin hacer nada o "haciendo la hora" porque no puedo llegar a la casa y tengo que esperar el bus. (Estudiante universitaria, 22 años).

\section{Transformaciones en la sociabilidad y redes}

Para algunos residentes, la vida en Santa Elena ha implicado transformaciones en sus vínculos sociales. El debilitamiento de redes de sociabilidad establecidas con anterioridad en la ciudad consolidada y la pérdida en la variedad de actividades recreativas que implican un contacto mayor con otras personas, constituyen un "costo importante" que, nuevamente, se compensa con el acceso a tranquilidad y espacio.

E1: Nos alejamos de los amigos que teníamos allá po'... en el fondo, ese ha sido un cambio importante... E2: Es un costo.

E1: Un costo importante que, claro, nosotros estábamos un poco claros que había que asumirlo, pero... las visitas, obviamente, son menos frecuentes. Las comodidades que teníamos como ir al cine, que lo teníamos al lado... ir a comer también... como que 
nos hemos limitado un poco más (...), pero lo bueno es que tenemos una tranquilidad que no teníamos allá, un espacio que no teníamos allá. (E1: Bioquímico, 37 años; E2: Bioquímica, 34 años).

Para esta pareja el cambio de residencia a Santa Elena ha implicado un costo social que es percibido como una pérdida. La distancia y el costo económico en el transporte es un tema relevante en el debilitamiento de aquellas redes sociales preexistentes, pues, como comenta un entrevistado, "estando en Santiago estai cerca de los amigos" y a ello agrega lo siguiente:

[Ahora] uno les dice a los amigos: "Ya ¿sabís qué? Mejor ven tú pa' acá" - "No, es que estai muy lejos"

- “bueno, entonces no nos juntamos po' hueón”. (Ingeniero, 40 años).

En los testimonios anteriores se alude al incremento de la distancia como factor que ha condicionado, en cierta medida, la vida cotidiana de los entrevistados. El debilitamiento de redes sociales preexistentes en la ciudad consolidada convive, de acuerdo con el relato de gran parte de ellos, con un fortalecimiento de redes vecinales intracondominio, pues reúne condiciones y atributos habitacionales que suscitan la vida en comunidad, como señala un entrevistado, "están dadas las condiciones acá para que tú compartas con otros”. (Psicólogo, 40 años).

Yo creo que me volví, por lo menos a nivel de vivienda, más sociable... me abrí un poco a la comunidad. Otra cosa es que se me generó un espacio familiar, individual -incluso de pareja- pa' compartir con más personas y disfrutar del tiempo libre. (Psicólogo, 40 años).

Las ideas anteriores suelen estar encadenadas con la alusión a sus viviendas previas, muchas de ellas departamentos ubicados en comunas de la ciudad consolidada, lo que es percibido como un espacio residencial que no suscita los vínculos fuertes entre vecinos. Pese al fortalecimiento de vínculos vecinales al interior del condominio, las actividades colectivas suelen estar circunscritas a la vivienda, pues de acuerdo con las observaciones en terreno, los espacios comunes se encuentran deshabitados durante gran parte del día.

\section{Transformaciones en las actividades cotidianas y acceso a servicios}

Tras el cambio de residencia a Santa Elena, algunos entrevistados señalan la pérdida de posibilidades para realizar actividades diversas sin previa planificación, además de una considerable disminución en la frecuencia de actividades como salir a comer o ir al cine. La proximidad a servicios en ciertas comunas de la ciudad consolidada suscita la realización de diversas actividades con mayor espontaneidad, donde podían efectuarse sin tener previa planificación. La posibilidad de tener opciones de fácil acceso frente a situaciones imprevistas sin la necesidad de que representaran una complejidad.

Cuando vivíamos en Providencia, teníamos un "OK Market" abajo... y lo cerraban a las 11 y media de la noche. Entonces, te faltara lo que te faltara, bajabai en pantuflas, ibai a comprar al frente, volviai y listo. No había ningún problema. Aquí no podís po'. Aquí, si te falta algo a las... 9 de la noche, ya... jodimos. (Ingeniero civil, 31 años).

En este sentido, y tal como lo experimentan algunos residentes con la movilidad en el bus, vivir en Santa Elena los ha llevado a programar diversas actividades de su vida cotidiana con mayor antelación, o incluso, anticiparse a situaciones imprevistas. En palabras de una entrevistada, "[con el cambio a Santa Elena] tuve que aprender a organizarme de mayor manera... con el tema de las compras, de todo". (Visitadora médica, 39 años).

Por otra parte, la distancia geográfica como limitante principal y la oferta de equipamientos y servicios aun escasamente diversificada en Santa Elena, comienza a suscitar entre los residentes un "consumo cultural doméstico" o, en palabras de una entrevistada, "una vida de casa". Esto es, que el tiempo libre es utilizado para estar en el condominio y realizar actividades "puertas adentro", ya que, como menciona un residente, "ahora nos da más lata salir”. (Ingeniero civil, 31 años). Se incrementan las 
reuniones con amigos del condominio en desmedro de relaciones sociales preexistentes, hacer fiestas y asados, tener vida social al interior del condominio o actividades vinculadas con el cuidado de la casa y el jardín. En la misma línea, algunos entrevistados señalan que existe un modo de vida particular también para los hijos, que no se condice con el que llevan los niños en la ciudad abierta. "La vida de los niños es muy de casas también, o sea los niños no es que vayan al mall a vitrinear... los niños acá se juntan en casas a ver películas, a conversar, a jugar”. (Abogada, 42 años).

\section{Transformaciones en la convivencia vecinal y estructuración del habitar}

Las transformaciones en la vida cotidiana no solo se remiten al ámbito de la movilidad o las redes de sociabilidad, sino que también a la convivencia vecinal y, específicamente, a la regulación de ciertas conductas mediante el reglamento interno de convivencia y copropiedad. Las asociaciones de residentes de administración del condominio se enuncian como órganos de control y regulación de la vida cotidiana dentro de los límites del proyecto. En este sentido, se trata de un nuevo tipo de gobernabilidad y de nuevas formas de control, emanadas no desde el Estado, sino que desde los mismos individuos. Lo anterior se traduce en mecanismos de hiperregulación de la vida cotidiana, y aquello que surge como un documento para minimizar los conflictos de convivencia se transforma, en algunos casos, en un desencadenante de estos.

En Santa Elena cada condominio maneja su propio reglamento, teniendo cada uno de ellos diversos grados de "severidad". Sin embargo, existen algunos factores comunes. En los reglamentos internos se indican todos los aspectos formales que se deben resguardar para mantener la estética original del condominio. Además, se entregan pautas de comportamiento y actividades que garanticen una sana convivencia vecinal.

En cuanto a la dimensión espacial, no se permite alterar la estética del condominio. No se puede modificar la arquitectura de las viviendas ni su aspecto exterior, como fachadas, cierres perimetrales o colores originales de los muros. En cuanto a las ampliaciones deben ser previamente consultadas con la administración, quien las aprueba o rechaza, e incluso controla el material con el que se realiza la intervención. Lo anterior tiene una connotación negativa para algunos vecinos, quienes lo perciben como un elemento que resta identidad individual, que no permite diferenciación entre unos y otros, tal como evidencia el siguiente relato:

E1: A mí en particular no me gusta que sea tan homogéneo y tan... ¡Poco natural! Tan cuadrado todo... que todo el condominio, el de acá, el de al lado, sean iguales, me carga la verdad. Que haya tanta restricción pa' poder cambiar las cosas eeh... me carga también, pero son las reglas del juego... E2: ... tan parejo... una película de Tim Burton (risas)... E1: ¡Exacto! Claro, como si fuéramos robots y todos iguales... (E1: Bioquímico, 37 años; E2: Bioquímica, 34 años).

En cuanto al reglamento de convivencia, se definen, entre otras cosas, los días y horarios para sacar la basura, los tipos de basureros que deben tener los residentes, la reglamentación interna de la velocidad de circulación vehicular, los días y horarios para cortar el pasto con máquinas a motor o las multas asociadas a la circulación de perros sin correa o sin el acompañamiento de sus dueños. Este documento es fundamental, pues estructura el comportamiento de los residentes y la vida en comunidad. Mientras algunos lo ven como algo positivo, señalando que "hay que saber vivir en comunidad", otros aluden a la excesiva estructuración que genera en el habitar cotidiano, considerando esta reglamentación como "exagerada".

Estábamos pensando cambiarnos de casa ahora, por el tema de ¡tanto que alegan acá! Alegan porque plantaste un árbol en el lado izquierdo y no en el lado derecho. No, son muy ataosos. (Ingeniera en alimentos, 44 años).

Mucha gente cree que porque se viene a vivir a una casa... es su casa, su metro cuadrado y le importa un cuesco el vecino y no, aquí formas parte de una 
comunidad y, como lo dice el nombre es: "como una unidad" y tienes que ceñirte a reglas y acuerdos. (Abogada, 42 años).

En definitiva, todos los residentes están conscientes de la influencia de la normativa interna en sus modos de habitar. Para algunos es algo aceptado y, a pesar de lo estricta que pueda resultar, la asumen como uno de los costos asociados de la vida en condominio. Sin embargo, para otros, las "reglas del juego" se perciben como impuestas y aun estando conscientes de la existencia del reglamento, lo consideran una exageración en el control de la vida cotidiana.

\section{Discusión}

De acuerdo con los resultados del caso analizado, las motivaciones para migrar hacia un espacio residencial cerrado periurbano surgen de manera dominante como la consecuencia de la búsqueda de atributos habitacionales como la casa y el patio, percibidos como adecuados para "hacer familia", y no necesariamente de la búsqueda declarada de distinción social o seguridad ciudadana frente a la violencia, delincuencia o crimen, como ha sido observado en otras investigaciones (Caldeira, 2007; Roitman; 2011). En este sentido, las motivaciones para vivir en un espacio residencial cerrado periurbano emergerían de manera dominante como consecuencia de la oferta residencial en el mercado habitacional de Santiago.

Reconociendo la existencia de lógicas de diferenciación social y alta valoración por las medidas de seguridad en el caso estudiado, la alusión secundaria a estas temáticas respecto de la búsqueda de atributos habitacionales puede interpretarse por la situación de aislamiento geográfico de Santa Elena en relación con su entorno inmediato. A diferencia de lo observado en otras investigaciones donde el cerramiento adquiere un rol disuasorio y diferenciador frente a la coexistencia de grupos sociales diversos en un mismo territorio (Rosenmann, 2017; Ruiz-Tagle, 2016a), en el caso analizado, la inexistencia de poblaciones colindantes y, en definitiva, el propio aislamiento geográfico como mecanismo de seguridad frente a desconocidos, puede ser motivo de su mención secundaria como factor determinante del cambio de residencia.

Este hallazgo en ningún caso invalida los aportes producidos en la literatura latinoamericana desde los enfoques de la distinción social y la seguridad como motores del cerramiento residencial, las cuales han contribuido a comprender los procesos de suburbanización de las élites o clases acomodadas tradicionales en otros contextos temporales y territoriales (Caldeira, 2007; Roitman, 2011). Más bien, complementa la comprensión de un fenómeno de periurbanización intensivo que se ha ido complejizando en las últimas décadas, en el cual - para el caso nacional y de acuerdo con otras investigaciones- la proliferación de esta nueva tipología de megaproyectos residenciales cerrados en la periferia metropolitana parece estar reproduciéndose como una estrategia de sofisticación de la industria inmobiliaria contemporánea (Vidal-Koppmann, 2008, 2012), antes que en el surgimiento de valores antiurbanos, búsqueda de distinción social o miedo al crimen.

Finalmente, en la búsqueda de atributos habitacionales que para los entrevistados son concebidos como un incremento en la calidad de vida se asumen costos sociales y económicos adicionales que inciden en los modos de habitar de quienes residen en Santa Elena, especial pero no únicamente, dados por el incremento de las distancias geográficas con redes prestablecidas. En línea con otras investigaciones (Cáceres Seguel, 2015), se evidencia que los nuevos proyectos residenciales privados tienen impactos significativos en la calidad de vida de sus habitantes, donde se accede a atributos habitacionales de alto estándar, pero otras dimensiones de la vida cotidiana como la movilidad, sociabilidad, acceso a equipamientos y servicios y formas de comportamiento se ven afectadas.

\section{Conclusiones}

La presente investigación exploró la relación entre los nuevos espacios residenciales cerrados periurbanos y los modos de habitar de sus residentes. Se ha evidenciado que tales espacios, como Santa Elena, cumplen un 
creciente rol modelador en los modos de habitar de estos, incidiendo en diversas dimensiones de la vida cotidiana. La presente investigación ha evidenciado cuatro: 1) movilidad cotidiana; 2) sociabilidad; 3 ) actividades cotidianas y acceso a servicios; 4) convivencia vecinal y estructuración del habitar. Estas transformaciones no solo inciden sobre las prácticas cotidianas, sino que, además, buena parte de ellas son percibidas por sus habitantes como costes sociales y económicos, partes del precio adicional que deben pagar por habitar estos espacios.

Existen diversas dimensiones de este modelo residencial periurbano que influyen directamente en los modos de habitar de sus habitantes. Entre los más relevantes se destaca la localización del condominio en el territorio y su distancia geográfica con respecto a la ciudad consolidada e inexistencia de transporte público en el sector. Lo anterior influye en los tiempos y experiencias de desplazamiento; la dependencia del automóvil y del transporte privado; el incremento en los costos de movilización; el debilitamiento de vínculos sociales preestablecidos y; a la vez, en el fortalecimiento de las relaciones sociales intracondominio; la pérdida y disminución en la frecuencia de actividades sociales y recreativas, dadas por la limitada oferta de servicios que no ha logrado la supuesta autonomía funcional con respecto a la ciudad consolidada; la regulación de múltiples pautas de comportamiento, establecidas por los reglamentos internos de copropiedad y convivencia, siendo la más evidente el condicionamiento de transformaciones a la vivienda (ampliaciones, colores, materiales, entre otras).

Habiendo una larga trayectoria de investigación en la materia y frente a la diversificación de las tipologías de espacios residenciales cerrados y su público objetivo, el escenario actual propone que estas nuevas ciudades privadas periurbanas proliferan no solo por la búsqueda de distinción social o por el miedo al crimen que pueda expresar una porción de la población, sino también, porque es un producto inmobiliario probado que recoge atributos habitacionales que serían difíciles de hallar en la ciudad consolidada, acorde con la capacidad de pago y endeudamiento de sus residentes. La búsqueda de condiciones como "la casa" y "el patio" - aspiraciones residenciales fuertemente arraigadas entre amplios grupos de población nacional-son atributos que se encuentran predominantemente en formato de condominio cerrado $y$, de manera creciente, en la periferia metropolitana de Santiago. Lo anterior evidencia un proceso socioespacial dialéctico, donde la producción del espacio periurbano se define como un proceso de influencias mutuas (Lefebvre, 1991), donde no solo se produce un espacio físico, sino también, un modo particular de habitar la periferia metropolitana y, en definitiva, una transformación en la vida cotidiana de los sujetos.

El presente artículo ha pretendido ser un aporte en la comprensión de los procesos contemporáneos de cerramiento residencial mediante megaproyectos periurbanos. En Chile el fenómeno descrito en este artículo se encuentra hasta el momento escasamente documentado desde perspectivas etnográficas orientadas a restituir el punto de vista de los propios habitantes de estos espacios. Asimismo, se ha pretendido aportar en términos teóricos, tensionando las nociones más recurrentes en la materia, como son la distinción social y la seguridad. Lo anterior advierte sobre el creciente peso que en el Chile neoliberal y, al alero de políticas públicas de desarrollo urbano condicionado, han adquirido holdings inmobiliarios no solo en la configuración de los espacios periurbanos contemporáneos (Cáceres Seguel, 2016; Lukas et al., 2020;), sino que también en el modelamiento y transformación de las prácticas cotidianas de sus habitantes.

\section{Referencias bibliográficas}

Aguilar, A. (2002). Las mega-ciudades y las periferias expandidas. EURE (Santiago), 28(85), 121-149. https:// dx.doi.org/10.4067/S0250-71612002008500007

Arizaga, C. (2000). Murallas y barrios cerrados. La morfología espacial del ajuste en Buenos Aires. Nueva Sociedad, (166), 22-32.

Arizaga, C. (2005). El mito de comunidad en la ciudad mundializada: estilos de vida y nuevas clases medias en urbanizaciones cerradas. El Cielo por Asalto. 
Auyero, J. y Swistun, D. (2007). Expuestos y confundidos. Un relato etnográfico sobre sufrimiento ambiental. Íconos, 0(28), 137-152. https://doi.org/10.17141/ iconos.28.2007.216

Borja, J. (2008). Miedos, segregación y mercado en la ciudad globalizada. Nueva Sociedad, (213), 25-34.

Borsdorf, A. (2003). Hacia la ciudad fragmentada. Tempranas estructuras segregadas en la ciudad latinoamericana. Scripta Nova, 7(146), 122. http://www.ub.edu/geocrit/ sn/sn-146\%28122\%29.htm

Cabrales, L. (2005). Estado del conocimiento sobre las urbanizaciones cerradas en Iberoamérica. En O. Gutiérrez (Coord.), La ciudad y el miedo (pp. 185-194). VII Coloquio de Geografía Urbana.

Cáceres Seguel, C. (2015). Ciudades satélites periurbanas en Santiago de Chile: paradojas entre la satisfacción residencial y precariedad económica del periurbanita de clase media. Revista INVI, 30(85), 83-108. https://doi. org/10.4067/s0718-83582015000300003

Cáceres Seguel, C. (2016). Ciudades satélites en Lampa, Santiago: un caso de co-gobierno urbano entre el municipio y holdings inmobiliarios. Cuadernos Geográficos, 55(2), 265-281.

Caldeira, T. (2007). Ciudad de muros. Gedisa.

Carrión, F. y Núñez, J. (2006). La inseguridad en la ciudad: hacia una comprensión de la producción social del miedo. EURE (Santiago), 32(97), 7-16. https://dx.doi. org/10.4067/S0250-71612006000300001

Chevalier, J. y Carballo, C. (2005). Los espacios residenciales cerrados: en busca del entre-sí. Estudio comparativo entre el norte y el sur del continente americano. Scripta Nova, 9(194), 53.

Colina junto a otras dos comunas concentran un tercio de la inversión inmobiliaria de Chile a 2021 (3 de noviembre de 2017). El Mercurio.
Contreras, Y., Castillo, O.y Sánchez, A. (2018). Manifestaciones de fragmentación urbana vinculadas a urbanizaciones cerradas: el caso del Municipio Metropolitano de Zinacantepec, Estado de México, 1990-2012. Revista de Urbanismo, (39), 1-15. https://doi.org/10.5354/0717-5051.2018.51288

Davis, M. (2003). Ciudad de cuarzo. Arqueología del futuro en Los Ángeles. Lengua de Trapo.

Espinosa, F. (2019). Movilidades cotidianas y nuevos modos de habitar: Un análisis en y desde la periferia metropolitana. Entorno Geográfico, (18). https://doi.org/10.25100/ eg.v0i18.8595

Espinosa, F., Vieyra, A. y Garibay, C. (2015). Narrativas sobre el lugar. Habitar una vivienda de interés social en la periferia urbana. Revista INVI, 30(84), 59-86. https://doi. org/10.4067/s0718-83582015000200003

Fernández, G., Salcedo, R. y Torres, A. (2004). De la publicidad inmobiliaria a la vivencia cotidiana: aspectos que permiten entender la evolución de las expectativas residenciales. En G. Cáceres y F. Sabatini (Eds.), Barrios cerrados en Santiago de Chile: entre la exclusión y la integración residencial (pp. 113-145). Pontificia Universidad Católica de Chile; Lincoln Institute of Land Policy.

Guber, R. (2011). La etnografía. Método, campo y reflexividad. Siglo XXI.

Gutiérrez, M. (9 de mayo de 2019). Plan inmobiliario residencial Santa Elena. Segundo mayor desarrollo de Chicureo pone en venta 11ha. El Mercurio.

Hidalgo, R. (2004). De los pequeños condominios a la ciudad vallada: las urbanizaciones cerradas y la nueva geografía social en Santiago de Chile (1990-2000). EURE (Santiago), 30(91), 29-52. https://dx.doi.org/10.4067/ S0250-71612004009100003

Hidalgo, R., Borsdorf, A. y Sánchez R. (2007). Hacia un nuevo tejido urbano. Los megaproyectos de ciudades valladas en la periferia de Santiago de Chile. Ciudad y Territorio Estudios Territoriales (CyTET), 39(151), 115-135. 
Janoschka, M. (2002). El nuevo modelo de la ciudad latinoamericana: fragmentación y privatización. EURE (Santiago), 28(85), 11-20. https://dx.doi.org/10.4067/ S0250-71612002008500002

Jirón, P. y Mansilla, P. (2014). Las consecuencias del urbanismo fragmentador en la vida cotidiana de habitantes de la ciudad de Santiago de Chile. EURE (Santiago), 40(121), 5-28.https://dx.doi.org/10.4067/S0250-71612014000300001

Lefebvre, H. (1991). The production of space. Blackwell.

Lefebvre, H. (2003). The urban revolution. University of Minnesota Press.

Ley $N^{\circ} 19.537$ de 1997. Sobre copropiedad inmobiliaria. 05 de diciembre de 1997. D.O.

Lukas, M., Fragkou, M. y Vásquez, A. (2020). Hacia una ecología política de las nuevas periferias urbanas: suelo, agua y poder en Santiago de Chile. Revista de Geografía Norte Grande, (76), 95-119. https://dx.doi.org/10.4067/S071834022020000200095

Meyer, K. y Bahr, J. (2004). La difusión de condominios en las metrópolis latinoamericanas. El ejemplo de Santiago de Chile. Revista de Geografía Norte Grande, (32), 39-53.

Pfannenstein, B., Martínez, J., Anacleto, E. y Sevilla, S. (2019). Planificación urbana y la influencia de las urbanizaciones cerradas: El Área Metropolitana de Guadalajara, México. Economía, Sociedad y Territorio, 19(59), 10871117. https://doi.org/10.22136/est20191278

Riffo, L. (2004). Los impactos de la globalización sobre los mercados de trabajo metropolitanos: El caso de Santiago de Chile en la década de los noventa. En C. De Mattos y M. Ducci, A. Rodríguez y G. Yáñez Warner (Eds.), Santiago en la globalización: ¿Una nueva ciudad? (pp. 167 -187). Ediciones SUR.

Roitman, S. (2003). Barrios cerrados y segregación social urbana. Scripta Nova, 7(146), 118. http://www.ub.edu/ geocrit/sn/sn-146(118).htm
Roitman, S. (2004). Urbanizaciones cerradas: estado de la cuestión hoy y propuesta teórica. Revista de Geografía Norte Grande, (32), 5-19.

Roitman, S. (2011). Distinción social y hábitat residencial en América Latina. Revista INVI, 26(73), 17-71. https://doi. org/10.4067/s0718-83582011000300002

Roitman, S. (2016). Urbanizaciones cerradas a escala planetaria. Prospectiva. Revista de Trabajo Social e Intervención Social, (21), 13-22. https://doi.org/10.25100/prts.v0i21.918

Rojo, F. (2015). Transformaciones urbanas vinculadas a barrios cerrados: evidencias para la discusión sobre fragmentación espacialenciudades latinoamericanas. Cuadernos de Geografía, 24(1), 121-133.http://dx.doi.org/10.15446/rcdg.v24n1.47776

Rosenmann, I. (2017). El muro: una significación de "clase social” segregada en la ciudad. Revista de Urbanismo, (36), 82-96. http://dx.doi.org/10.5354/0717-5051.2017.45176

Ruiz-Tagle, J. (2016a). La persistencia de la segregación y la desigualdad en barrios socialmente diversos: un estudio de caso en La Florida, Santiago. EURE (Santiago), 42(125), 81-108. https://dx.doi.org/10.4067/ S0250-71612016000100004

Ruiz-Tagle, J. (2016b). La segregación y la integración en la sociología urbana: revisión de enfoques y aproximaciones críticas para las políticas públicas. Revista INVI, 31(87), 9-57.https://doi.org/10.4067/s0718-83582016000200001

Sabatini, F. (2000). Reforma de los mercados de suelo en Santiago, Chile: efectos sobre los precios de la tierra y la segregación residencial. EURE (Santiago), 26(77), 4980. https://dx.doi.org/10.4067/S0250-71612000007700003

Sabatini, F. y Cáceres, G. (2004). Los barrios cerrados y la ruptura del patrón tradicional de segregación en las ciudades latinoamericanas: el caso de Santiago de Chile. En G. Cáceres y F. Sabatini (Eds.), Barrios cerrados en Santiago de Chile: entre la exclusión y la integración residencial (pp. 9-43). Pontificia Universidad Católica de Chile; Lincoln Institute of Land Policy. 
Salcedo, R. y Torres, A. (2004). Los nuevos barrios enrejados: ¿muro o frontera? En G. Cáceres y F. Sabatini (Eds.), Barrios Cerrados en Santiago de Chile: entre la exclusión y la integración residencial (pp. 147-177). Pontificia Universidad Católica de Chile; Lincoln Institute of Land Policy.

Segura, R. y Chaves, M. (2019). Modos de habitar: localización, tipo residencial y movilidad cotidiana en el Gran La Plata. En M. Di Virgilio y M. Perelman (Eds.), Disputas por el espacio urbano. Desigualdades persistentes y territorialidades emergentes (pp. 193-222). Biblos.

Stockins, P. (2004). Oferta y demanda de vivienda en la periferia santiaguina: los nuevos desarrollos inmobiliarios. En G. Cáceres y F. Sabatini (Eds.), Barrios cerrados en Santiago de Chile: entre la exclusión y la integración residencial (pp. 83-111). Pontificia Universidad Católica de Chile; Lincoln Institute of Land Policy.

Svampa, M. (2001). Los que ganaron: la vida en los countries y barrios privados. Biblos.

Teixeira de Andrade, L. (28 de mayo -1 de junio de 2001). Condominios Fechados da Região Metropolitana de Belo Horizonte: novas y velhas experiencias [Sesión de conferencia]. IX Encontro Nacional da Associaçao Nacional de Pós-Graduação e Pesquisa em Planejamento Urbano e Regional (ANPUR), Rio de Janeiro, Brasil.

Vidal-Koppmann, S. (2008). Mutaciones metropolitanas: de la construcción de barrios cerrados a la creación de ciudades privadas: balance de una década de urbanización privada en la región metropolitana de Buenos Aires. Scripta Nova, 12(270), 111.

Vidal-Koppmann, S. (2012). Ciudades privadas del siglo XXI. Nuevas estrategias del mercado inmobiliario en la periferia metropolitana de Buenos Aires. Revista Contexto, (6), 69-86. 